frequent and well placed strokes of the editor's pen. The aim has undoubtedly been to publish an almost encyclopaedic authoritative reference work covering the developments in the entire interferon field up to the time of the writing of the individual contributions. This goal has largely been met. Omissions of significant work published before 1970 seem to have been few.

There is a wealth of detailed factual information. Thus, a total of sixty-six different viruses is listed under the heading "Some [sic] viruses which induce interferon", arranged in a table spread over four pages, and also including information about the animal species in which interferon production was reported, with the appropriate references. An individual wishing to accumulate this information on his or her own would probably have to spend weeks toiling in the library. A chapter entitled "Factors Influencing Interferon Production" (by M. Ho) occupies more than thirty pages.

Interferon research is a mixed bag. Rooted in virology, it has been branching out increasingly into other areas of microbiology, as well as chemistry, cell biology, molecular biology, immunology and tumour biology. These different facets of interferon work are represented in the book, although the main emphasis is on the role of interferon in the natural defence against viruses (chapter by S. Baron) and a considerable portion of the treatise is devoted to the description of antiviral effects of interferons and inducers in man and animals (N. B. Finter). There is, however, a new chapter on non-viral substances which induce interferon (T. C. Merigan). Also most welcome is the addition of a chapter by M. N. Oxman reviewing on some 90 pages interferon production by tumour viruses and tumour cells, as well as various aspects of the action of interferon and interferon inducers on tumour viruses and tumour cells, both in animals and cell cultures.

Most chapters were apparently written in about 1970. The delay in publication, the editor explains in the preface, was mainly because some contributions had been received late. Unfortunately, the hiatus has already made obsolete portions of the otherwise nicely written chapters on the mechanisms of interferon production (D. C. Burke), purification (K. H. Fantes) and mechanism of action (J. A. Sonnabend and R. M. Friedman). A further consequence of the delay is the absence of any description of some biological activities of interferon on uninfected cells which have only been recognised in the past three years.

The bibliography, listing 1,500-odd references, is arranged in alphabetical order and includes the complete titles of articles. Each reference is followed by the page numbers on which it is cited in the book, so the bibliography also serves as a sort of an author index: a clever idea. The subject index is both extensive and well arranged.

The book wil be apreciated mainly as a reference guide for those who have more than a passing affair with interferon. Portions of the book, however, can be useful to readers who wish to obtain more general information about some aspects of interferon work; they will benefit from the very readable introductory chapter outlining the chronology of major developments in interferon research (K. Cantell) and from the neat summaries at the end of each of the seventeen chapters. JAN VILCEK

\section{Mycoplasma Monograph}

The Biology of Mycoplasmas. By Paul F. Smith. Pp. $\mathrm{x}+257$. (Academic: New York and London, August 1971.) $\$ 14.50 ; £ 6.75$.

IN the preface, the author states that his aim is to acquaint the general biological scientist with a group of microorganisms which could be used to study basic biological mechanisms. Because of this, we have a monograph which deals more comprehensively with the biochemistry and physiology of mycoplasmas than any recent book or review on these microorganisms. Although Professor Smith disclaims any intention to provide a reference book, he has assembled and integrated the biochemical information so ably under appropriate headings that the monograph should prove useful for reference. In this connexion, the inclusion of further sub-headings in the contents would be helpful.

The author's interest in the origin of mycoplasmas is obvious in both the first and last chapters; he favours the highly plausible hypothesis that mycoplasmas have evolved from bacterial ancestors by losing the rigid cell wall and that this has enabled them to establish a nearly true parasitic relationship with their hosts. Comparisons of mycoplasmas with some existing bacteria have failed to show any relationship, but Professor Smith points out the limitations of the comparisons so far made. Although a relationship with some remote bacterial ancestor seems more likely than a relationship with an existing bacterium, the author's arguments may serve to counterbalance the present tendency to discount the possibility of any relationship between mycoplasmas and bacteria.

The inclusion of a chapter on the relationship of structure to function (chapter 4), an aspect largely ignored in recent books on mycoplasmas, is commendable. This correlates, as far as is possible at present, the information on structure and the dynamics of growth and reproduction provided in chapters 2 and 3. Diagrams illustrating the author's theory of membrane permeation and two types of respiratory pathway are especially helpful.

The section dealing with host-parasite interactions in chapter 5 is less detailed than the rest of the monograph. This subject is of limited interest to cell biologists, however, and has been more fully covered in two recent books.

I should like to have seen the generic name Acholeplasma applied to those mycoplasmas which do not require sterols for growth, and the name Mycoplasma reserved for those which are sterol-dependent. This reluctance to adopt the new nomenclature may, however, be related to Professor Smith's theory on the relationship of sterols to polyterpene biosynthesis in mycoplasmas, a theory which is most compellingly argued in chapter 3 .

Mycoplasmas are already being exploited by biologists interested in membrane function and structure. It is to be hoped that this book will direct the attention of other cell biologists to the potentialities of mycoplasmas in the study of biological mechanisms. In this connexion, the speculations in Professor Smith's final chapter on the significance of mycoplasmas as cells are stimulating and could provide a basis for further experimentation.

Ruth M. LEMCKE

\section{Abyssal Animals}

Abyssal Environment and Ecology of the World Oceans. By Robert J. Menzies, Robert Y. George and Gilbert T. Rowe. Pp. xxiii + 488. (Wiley: New York and London, May 1973.) £12.50.

THE abyssal environment, although most representative of the Earth's surface in terms of area covered, is yet almost certainly the least known. A growing interest in the abyssal fauna reflects increasing concern of its possible perturbation, by exploitation of deep mineral resources and the dumping of industrial waste, when its origin, structure and metabolism are still virtually unknown to us.

This book traces the beginnings of deep-sea biology. It also includes notes and photographs of contemporary workers judged to have contributed significantly to the subject. Sampling devices are reviewed, but a balanced discussion of the most successful samplers in current use is not provided. The various schemes for classifying the bathymetric distribution of the marine benthos as a whole are outlined and an original hierarchical system, based on the rate of change of the component genera and species in terms of the percentage of taxa common to samples, is proposed. Discussion of faunal distribution in the northwestern Atlantic is based mainly 